\title{
IMPLEMENTAÇÃO DO MÉTODO DE ENSINO PEER INSTRUCTION COM O AUXÍLIO DOS COMPUTA- DORES DO PROJETO "UCA" EM AULAS DE FÍSICA DO ENSINO MÉDIO ${ }^{+*}$
}

\author{
Maykon Gonçalves Müller \\ Aluno do Mestrado Acadêmico do Programa de Pós-Graduação em \\ Ensino de Física do Instituto de Física - UFRGS \\ Rafael Vasques Brandão \\ Colégio de Aplicação - UFRGS \\ Ives Solano Araujo \\ Eliane Angela Veit \\ Instituto de Física - UFRGS \\ Porto Alegre - RS
}

\section{Resumo}

Este trabalho apresenta resultados de um estudo de caso exploratório, cujos objetivos principais foram avaliar a receptividade dos alunos em relação ao método Peer Instruction (PI) e ao uso dos computadores do projeto "UCA" (Um Computador por Aluno); investigar se a discussão entre os colegas favorece a convergência para a resposta correta em testes conceituais, como tem sido apontado na literatura; e verificar a viabilidade do emprego dos computadores do projeto "UCA" como sistema de votação para a metodologia. O estudo foi realizado com uma turma de 34 alunos de terceiro ano do Ensino Médio de uma escola pública federal, ao longo de uma sequência didática sobre tópicos de Eletromagne-

\footnotetext{
Implementation of Peer Instruction Method of teaching with the aid of computers of the UCA project in High School Physics lessons

* Recebido: fevereiro de 2012. Aceito: maio de 2012.
} 
tismo. Neste estudo, observou-se que as discussões entre os colegas mostraram-se frutíferas, propiciando a participação ativa dos alunos e levando à convergência para a resposta correta. Concluiu-se que a metodologia pode ser aplicada com sucesso no contexto de uma sala de aula de ensino médio, utilizando os UCAs como sistema de votação, dadas as condições de infraestrutura para usá-los pelo período de duração da aula (e.g. carga nas baterias). Cabe ressaltar que a adoção do PI pode ser feita de modo complementar às atividades de resolução de problemas, trabalho experimental elou simulação computacional, voltadas para o ensino.

Palavras-chave: Peer Instruction. UCA. Ensino de Física.

\begin{abstract}
This paper presents results of an exploratory case study which the main objectives were to: evaluate the receptivity of the students regarding the Peer Instruction (PI) method and the use of computers of the UCA project (Brazilian version of the project One Laptop per Child); investigate if the discussion between colleagues promotes the convergence to the correct answer in concept tests, as it has been pointed in literature; and investigate the viability of using the UCA computers as a voting system to the methodology. The study was conducted in a class of 34 students in the third year of a Federal Public High School over an instructional sequence on topics of Electromagnetism. In this study we observed that the discussion among colleagues proved fruitful, allowing the participation of students and leading to the convergence to the correct answer. We conclude that this methodology can be successfully implemented in the context of a High School classroom using the UCAs as a voting system, given the conditions of infrastructure to use them for the duration of a lesson (e.g. charging of the batteries). It should be emphasized that the adoption of PI can be done in a complementary manner to the activities of problem solving, experimental work and/or computer simulation, aimed at teaching.
\end{abstract}

Keywords: Peer Instruction. OLPC. Physics Education. 


\section{Introdução}

Sabe-se que ensinar Física não é tarefa fácil. Dentre os principais desafios docentes, destaca-se a falta de motivação dos alunos para a aprendizagem dos conteúdos. Em boa parte, tal desmotivação é atribuída à forma como o ensino é organizado, mais especificamente às formas passivas de transmissão e aquisição de informações que ainda hoje são lugar comum nas salas de aula. Entretanto, as mesmas metodologias educacionais têm sido empregadas por séculos, apesar dos resultados obtidos estarem aquém dos desejados. Os alunos, por muitas vezes, acabam encarando a disciplina como uma mera memorização de fórmulas, sem qualquer significado físico e sem nenhuma conexão com o cotidiano.

Aliado a isso, o cenário tecnológico escolar é desconexo com a realidade fora da sala de aula. Vivemos uma época de grandes avanços tecnológicos, na qual a nova geração de jovens tem os computadores, em geral, como um instrumento básico de comunicação, diversão e aquisição de informações. Todavia, tal recurso ainda precisa encontrar seu espaço como ferramenta potencialmente útil para auxiliar uma aprendizagem mais efetiva de conceitos e construção de habilidades, tanto no mundo em geral, quanto no Brasil, em particular.

Indubitavelmente, a escola precisa se reformular para melhor contribuir para o desenvolvimento da sociedade contemporânea da qual o aluno faz parte, preparando-o adequadamente para os desafios do mundo atual, tornando o ensino mais atrativo ao aluno e, quiçá, melhorando a aprendizagem dos conteúdos disciplinares. Atualizar a escola implica tanto a obtenção de recursos materiais, como também o emprego de propostas pedagógicas e metodológicas que considerem, entre outros recursos, o uso eficaz das tecnologias na educação escolar.

Visando contemplar essa necessidade, o Governo Federal brasileiro, em 2007, formalizou o projeto UCA (Um Computador por Aluno), inspirado no projeto norteamericano OLPC (One Laptop Per Child). O projeto UCA, conhecido também como PROUCA ${ }^{1}$, possui como objetivo:

Promover a inclusão digital nas escolas das redes públicas de ensino federal, estadual, distrital, municipal ou nas escolas sem fins lucrativos de atendimento a pessoas com deficiência, mediante a aquisição e a utilização de soluções de informática, constituídas de equipamentos de informática, de

\footnotetext{
${ }^{1}$ Para maiores informações, visitar a página do projeto: <http://www.uca.gov.br>.
} 
programas de computador (software) neles instalados e de suporte e assistência técnica necessários ao seu funcionamento (Lei no 12.249 - Art. 7o $)^{2}$.

No entanto, sabe-se que apenas a presença dos computadores nas escolas não mudará o processo educacional atual. A inclusão dessa ferramenta em um ambiente formal de ensino pode até motivar os alunos, mas não há qualquer garantia de que aprendam de maneira mais significativa. Segundo Valente,

a verdadeira função do aparato educacional não deve ser a de ensinar, mas sim a de criar condições de aprendizagem. Isto significa que o professor deve deixar de ser o repassador do conhecimento - o computador pode fazer isto e o faz muito mais eficientemente do que o professor - e passar a ser o criador de ambientes de aprendizagem e o facilitador do processo de desenvolvimento intelectual do aluno (VALENTE, 1993, p. 5).

As teorias construtivistas afirmam que o ser humano constrói o conhecimento através da interação com o meio externo e entre os indivíduos à sua volta (VYGOTSKY, 1991; GOWIN, 1981; NOVAK, 1981). Transpondo tais teorias para a sala de aula, devemos estimular a interação dos estudantes com os materiais e as ferramentas oferecidas pelas instituições, bem como a interação entre os próprios estudantes e destes com o professor.

Tais constatações colocam-nos diante das seguintes questões: como inserir, no ambiente escolar, ferramentas tecnológicas (em especial o computador) e, ao mesmo tempo, engajar os estudantes ativamente no processo de ensinoaprendizagem? Quais metodologias de ensino favoreceriam tal inserção?

Algumas metodologias de ensino inovadoras vêm sendo empregadas com sucesso em âmbito internacional, para promover tal engajamento. Podemos destacar dois métodos: o Just-in-Time Teaching (NOVAK et al., 1999) e, em especial, o Peer Instruction (MAZUR, 1997) ou "Instrução pelos Colegas" (IpC), em uma tradução livre.

O IpC foi proposto para o Ensino Superior em meados da década de 90 do século passado pelo Prof. Eric Mazur, da Universidade de Harvard (EUA). Nos últimos anos, o método se difundiu rapidamente pelo mundo, sendo atualmente empregado por mais de trezentos professores em vinte e três países, com especial

${ }^{2}$ Disponível em $<$ http://www.uca.gov.br/institucional/noticiasLei12249.jsp >. Acesso em: 23 jan. 2012.

3 Usaremos, ao longo do artigo, a tradução livre "Instrução pelos Colegas" para a expressão Peer Instruction. 
destaque para seu uso em universidades norte-americanas, canadenses e australianas (CROUCH et al., 2007).

Esse método prevê que o professor limite a exposição inicial de um conceito ou conteúdo a não mais do que vinte minutos, quando então apresenta um Teste Conceitual $^{4}$ de escolha múltipla, a ser respondido individualmente pelos alunos (aproximadamente dois minutos) (MAZUR, 1997). As respostas dos alunos podem ser informadas ao professor de diversas maneiras, entre elas encontram-se sistemas eletrônicos de respostas ( clickers $^{5}$ ), cartelas coloridas (flashcards), computadores e outros dispositivos eletrônicos conectados à Internet.

Caso a frequência de acertos se situe entre $35 \%$ e $70 \%$, os alunos são orientados a formar pequenos grupos, preferencialmente com colegas que tenham optado, no Teste Conceitual, por alternativas diferentes, e discutir por cerca de três minutos, quando votam novamente. O objetivo é que os alunos reflitam individualmente e, depois, discutam em grupo suas respostas, antes do professor informar qual é a correta.

Crouch et al. (2007) afirmam que é fundamental para o sucesso do método escolher Testes Conceituais adequados. As questões devem ser criadas, ou selecionadas, segundo as dificuldades dos alunos e abordar um único conceito relevante. Além disso, não devem testar a memória ou a simples substituição de números em equações.

Um dos fatores a ser avaliado, ao inserir o IpC em sala de aula, é qual sistema de votação utilizar. As cartelas coloridas, bem como o simples levantar de mãos, são opções que envolvem pouco ou nenhum investimento financeiro por parte das escolas. Lasry (2008) realizou um estudo a fim de comparar a eficácia do uso de sistemas de votação eletrônica (clickers) e cartelas coloridas (flashcards). Em termos de aprendizagem, os resultados encontrados foram os mesmos; entretanto, em termos de ensino, os clickers mostraram-se melhores por facilitarem a contagem das votações, por não permitirem que um estudante veja o que o outro está marcando no momento da votação e, também, por manterem um registro das opções individuais, que pode ser usado para acompanhar a evolução dos alunos em direção aos objetivos de aprendizagem. Apesar dos benefícios, os gastos para a

\footnotetext{
${ }^{4}$ MAZUR (1997) cunhou o termo Conceptest para designar os tipos particulares de testes conceituais usados no IpC.

Espécie de controle remoto sem fio que se comunica com o computador do professor para registro das respostas dos alunos.
} 
aquisição de sistemas eletrônicos por parte das escolas não é desprezível e pode ser um empecilho para que o IpC chegue à sala de aula.

Dessa forma, faz-se relevante a busca por alternativas que facilitem a inovação pedagógica em sala de aula, particularmente, no caso deste trabalho, o emprego do IpC, através de recursos disponíveis nas escolas. Tendo em vista o recente investimento na aquisição dos computadores do projeto UCA para as escolas, optamos por investigar suas potencialidades como sistema de votação eletrônica em ambiente de sala de aula.

No presente trabalho, apresentamos resultados de um estudo de caso único, do tipo exploratório, realizado com uma turma de terceiro ano do Ensino Médio (EM) de uma escola pública federal, ao longo de uma sequência didática sobre tópicos de Eletromagnetismo. O estudo foi dividido em duas etapas: na primeira, relatada neste artigo, avaliamos a receptividade dos alunos em relação ao método IpC e ao uso dos computadores do projeto "UCA" (Um Computador por Aluno), investigamos se a discussão entre os colegas favorece a convergência para a resposta certa aos testes conceituais propostos, como tem sido apontado na literatura (MAZUR, 1997; CROUCH et al., 2007; CROUCH; MAZUR, 2001; BUTCHART et al., 2009) e verificamos a viabilidade do emprego dos UCAs ${ }^{6}$, como instrumentos para a implementação do método IpC; na segunda etapa, dever-se-á investigar a aprendizagem significativa de conceitos de Eletromagnetismo, bem como analisar o desempenho em um teste conceitual.

Dedicaremos a próxima seção para a apresentação do método IpC e, em seguida, passaremos à contextualização e aos resultados do estudo realizado.

\section{O método Instrução pelos Colegas (Peer Instruction)}

O IpC é uma metodologia de ensino que tem como principal objetivo tornar as aulas mais interativas, distanciando-se, assim, do ensino tradicional, no qual os alunos, em geral, são totalmente passivos em sala de aula.

Conforme o próprio nome sugere, uma das ideias centrais do método é fazer com que os alunos interajam entre si ao longo das aulas, ensinando uns aos outros os conceitos estudados e tentando aplicá-los na solução das questões conceituais apresentadas. Com isso, o método tenta ao máximo envolver ativamente os alunos na sua própria aprendizagem.

O método IpC, descrito por Mazur (1997) e Crouch et al. (2007), pode ser dividido em nove momentos durante as aulas, como segue.

1. Uma curta apresentação oral sobre os elementos centrais de um dado conceito ou de uma dada teoria é feita por cerca de vinte minutos.

\footnotetext{
${ }^{6}$ Por associação ao projeto, os próprios computadores são chamados de "UCAs".
} 
2. Uma pergunta de múltipla escolha, geralmente conceitual, denominada Teste Conceitual, é colocada aos alunos sobre o conceito (teoria) apresentado na exposição oral.

3. Os alunos têm entre um e dois minutos para pensarem silenciosamente sobre a questão apresentada.

4. Os estudantes registram suas respostas individualmente e as mostram ao professor, usando algum sistema de respostas (por ex., clickers ou flashcards).

5. De acordo com a distribuição de respostas, o professor pode passar para o passo seis (quando a frequência de acertos está entre 35\% e 70\%), ou diretamente para o passo nove (quando a frequência de acertos é superior a 70\%).

6. Os alunos discutem a questão com seus colegas por um a dois minutos.

7. Os alunos registram sua resposta revisada e as mostram ao professor, usando o mesmo sistema de respostas do passo 4.

8. O professor tem um retorno sobre as respostas dos alunos a partir das discussões e pode apresentar os resultados para os alunos.

9. O professor, então, explica a resposta da questão aos alunos e pode ou apresentar uma nova questão sobre o mesmo conceito ou passar ao próximo tópico da aula, voltando ao primeiro passo.

Perguntas, cuidadosamente escolhidas, fornecem aos alunos a oportunidade para descobrirem e retificarem seus erros. Por conseguinte, no decorrer do processo, proporciona a aprendizagem de conceitos relevantes por meio das discussões entre colegas.

Pesquisas realizadas na educação básica têm apontado que o desempenho de alunos que aprenderam com a metodologia $\mathrm{IpC}$ é superior ao de alunos em turmas tradicionais (FAGEN, 2002; CROUCH et al., 2007). Além disso, algumas pesquisas mostram que a aprendizagem se torna ainda mais expressiva quando o Just-in-Time Teaching é utilizado em conjunto com o IpC (MAZUR; WATKINS, 2007; CROUCH et al., 2007; CROUCH; MAZUR, 2001).

O essencial para o bom desenvolvimento do método está na distribuição de frequências das respostas dos alunos, que deve estar entre $35 \%$ e $70 \%$ de acertos. Nesse caso, a turma é dividida em pequenos grupos (em média três alunos), para discutirem a questão conceitual.

Na medida do possível, os grupos devem ser organizados de modo que reúnam alunos que optaram por diferentes alternativas na questão conceitual. Nesse momento, há um processo de interação e convencimento entre os alunos; os que 
apresentam argumentos mais plausíveis encorajam os demais a substituírem suas respostas.

\section{Metodologia de pesquisa}

Levando em consideração os objetivos do presente trabalho, o enfoque metodológico possui um caráter predominantemente qualitativo. Pesquisas qualitativas possuem características pontuais que dão suporte à nossa escolha. Na sequência, descreveremos brevemente tais características e apresentaremos o tipo de metodologia escolhida dentro dessa abordagem.

O interesse central da pesquisa interpretativa é a "busca por uma interpretação dos significados atribuídos pelos sujeitos a suas ações em uma realidade socialmente construída" (MOREIRA, 2012, p.76). Para tal, o pesquisador precisa estar imerso no contexto social em que o fenômeno se apresenta e observá-lo atentamente, recorrendo a tantos registros de dados quanto possíveis, para viabilizar uma interpretação de qualidade.

As pesquisas interpretativas têm um caráter exploratório, construtivo e descritivo, nas quais o pesquisador desenvolve novas hipóteses e fundamenta a teoria a partir dos dados coletados. Estes são coletados em ambientes naturais, no contexto em que ocorrem os comportamentos a serem estudados, por meio de entrevistas, observações, notas de campo, questionários com escalas e questionários de perguntas abertas.

Dentro do enfoque interpretativo de pesquisa, encontram-se diversas metodologias com características específicas. Para o presente trabalho, escolhemos o estudo de caso como metodologia de pesquisa, com enfoque na perspectiva de Yin. YIN (2005, p. 39) afirma que:

o estudo de caso é uma investigação empírica que investiga um fenômeno contemporâneo em profundidade e em seu contexto de vida real, especialmente quando os limites do fenômeno e o contexto não são claramente evidentes.

Segundo Yin, os estudos de caso são ideais para investigações que apresentam questões do tipo "como?" e "por quê?", e podem ser utilizados em, pelo menos, quatro situações diferentes. Tais situações são diferenciadas por seus objetivos específicos, são estes (Ibid., p. 41):

- Explicar os vínculos causais previstos nas intervenções da vida real;

- Descrever uma intervenção e o contexto da vida real na qual ela ocorreu;

- Ilustrar determinados tópicos em avaliação, de maneira descritiva; 
- Explorar situações em que a intervenção sendo avaliada não possui um único e claro conjunto de resultados.

O caso estudado foi uma turma do terceiro ano do EM de uma instituição pública federal, o Colégio de Aplicação da UFRGS, na cidade de Porto Alegre RS, no segundo semestre de 2011, na qual foi implementada a metodologia de ensino IpC com o auxílio dos computadores do projeto UCA. A metodologia foi aplicada ao longo de uma sequência didática sobre Eletromagnetismo.

Quanto às características específicas da turma selecionada, a mesma era composta por trinta e quatro estudantes, catorze do gênero masculino e vinte do gênero feminino. A idade média dos alunos que a compunham era de aproximadamente dezessete anos e o respectivo nível socioeconômico intermediário (classe média).

Com o objetivo de investigar em profundidade o contexto do estudo realizado, foram observados quatro meses de aula dessa turma, dois deles anteriores ao uso do método $\mathrm{IpC}$ e os outros dois durante a implementação desse método. Como instrumentos de coleta de dados, além do caderno de campo, foram registradas em vídeo cerca de vinte e uma horas-aula da disciplina de Física, antes e durante a aplicação do método; foi aplicado um questionário para coletar a opinião dos alunos; foram realizadas entrevistas semiestruturadas e avaliados os resultados das votações nos Testes Conceituais.

Este estudo faz parte de um trabalho de mestrado que busca investigar o uso de ferramentas computacionais como instrumentos para a inovação didática no ensino de Física. Além dos objetivos declarados no presente trabalho, este estudo de caso tem, ainda, como motivação, o levantamento de hipóteses e o melhor entendimento do método IpC em ação.

\section{Relato de experiência}

A duração do estudo foi de aproximadamente quatro meses, sendo os dois primeiros reservados para observações e familiarização dos estudantes com a presença do pesquisador em sala de aula, e até mesmo com a própria filmagem das aulas. Apesar de auxiliar o professor da disciplina com o andamento das aulas, o pesquisador não exerceu papel docente. O IpC foi utilizado nos dois meses finais, com um total de sete encontros de dois períodos de quarenta e cinco minutos.

A escola possuía duas turmas de terceiros anos. O principal aspecto levado em consideração para selecionar em qual das turmas o estudo seria realizado foi a distribuição das aulas ao longo da semana. A turma selecionada tinha dois encon- 
tros semanais de dois períodos em sequência, já a outra turma possuía três encontros semanais, dois de um período e outro de dois períodos. Optamos por períodos contíguos, tendo em vista os preparativos necessários para cada encontro.

Conforme mencionado anteriormente, a sequência didática proposta para o trabalho abordava tópicos de Eletromagnetismo. Os sete tópicos selecionados, planejados para serem desenvolvidos um por encontro, foram campo magnético gerado por um fio retilíneo, uma espira e um solenoide percorridos por corrente elétrica; força entre fios paralelos percorridos por corrente elétrica; força eletromotriz induzida; Lei de Faraday; Lei de Lenz e o funcionamento do transformador elétrico.

Para a execução do projeto, foi necessário escolher qual sistema/software utilizar nos notebooks para captar as respostas dos alunos. Optamos pelo aplicativo Google Forms, ferramenta gratuita pertencente ao pacote de aplicativos Google Docs, que permite criar formulários e disponibilizá-los on-line para serem respondidos. Para cada formulário criado, o aplicativo produz uma tabela contendo todas as informações coletadas. Além disso, possui opções que mostram o resumo das respostas (ver Fig. 1). Caso a pergunta seja de múltipla escolha, o resumo é apresentado em forma de gráficos de frequência. Essa opção foi usada para cada rodada de votação e facilitou muito o trabalho do pesquisador e do professor.

Criaram-se, então, para cada encontro, formulários que serviam como grade de respostas aos Testes Conceituais. Em cada formulário, o aluno deveria colocar seu número da chamada para identificá-lo, a alternativa que escolheu para responder ao Teste Conceitual apresentado e o grau de confiança em relação à sua resposta, em uma escala de três níveis: alto, médio e nulo. Tal medida foi tomada para buscar indicativos de mudança no grau de confiança após as discussões. Todavia, tais dados não foram analisados e incluídos na discussão dos resultados, pois isso foge do escopo do presente artigo.

Os Testes Conceituais foram apresentados com um projetor multimídia, conectado ao computador do pesquisador, que poderia ser consultado a qualquer instante pelo professor da disciplina.

Para cada rodada de votações, o formulário era editado para receber as respostas da questão apresentada. As questões eram liberadas gradativamente, para evitar que os alunos fossem tentados a responder todas de uma única vez, ou, ainda, que votassem na questão errada. Alguns dos Testes Conceituais podem ser

\footnotetext{
${ }^{7}$ Disponível em: $<$ http://docs.google.com>.
} 
vistos no Apêndice A e um dos formulários respondidos pelos alunos é ilustrado na Fig. 2, podendo também ser acessado no link: <http://is.gd/uca030>.

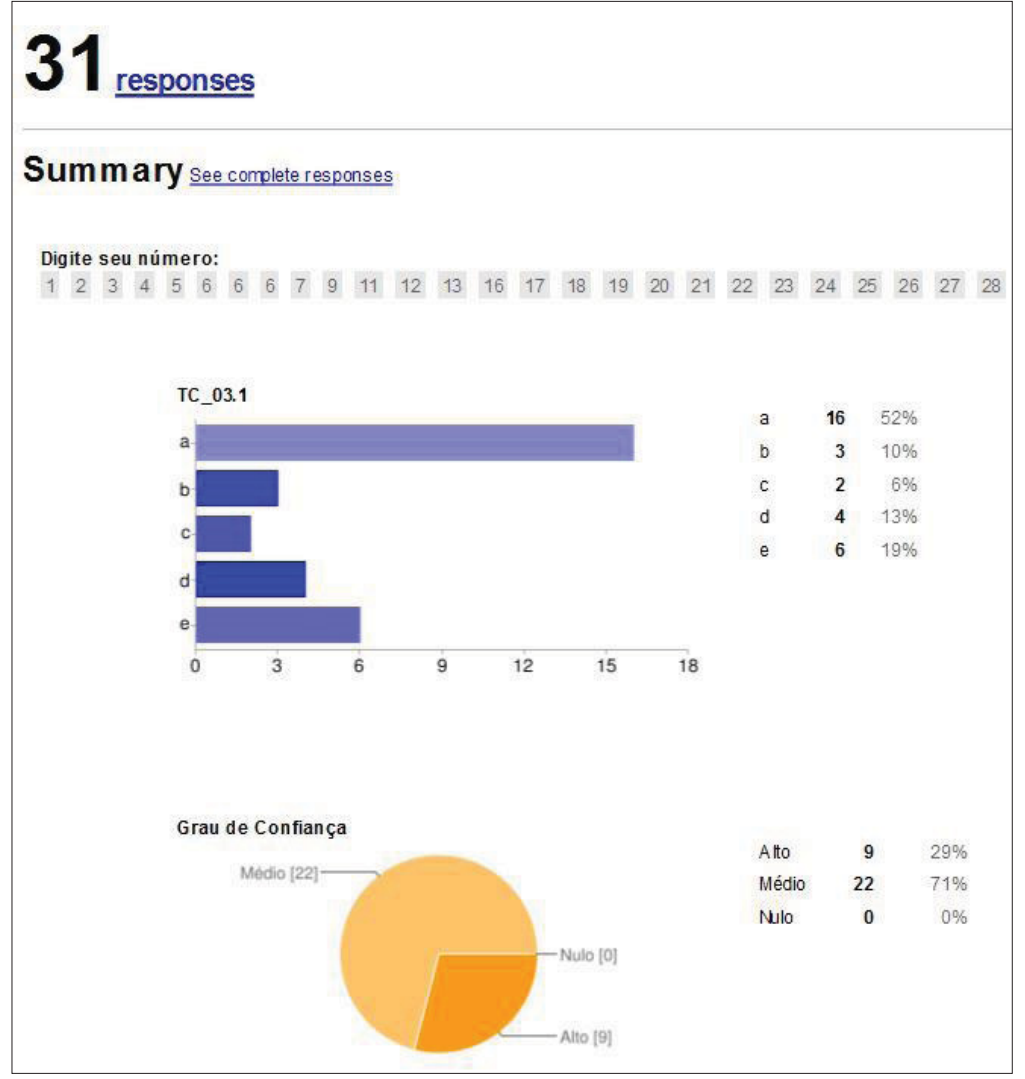

Fig. 1 - Sumário das respostas dos alunos a um Teste Conceitual fornecido pelo Google Forms.

Para facilitar o acesso ao formulário, criamos, nos navegadores da Internet dos notebooks, um atalho para o formulário. Dessa forma, os alunos, ao votarem, apenas abriam o navegador, clicavam no atalho e votavam. Essa medida também foi tomada para evitar dispersões na hora da votação. Outra medida adotada foi a de manter os notebooks com as baterias carregadas, evitando a necessidade de estarem conectados à rede elétrica e, como consequência, proporcionando aos estudantes maior mobilidade. 


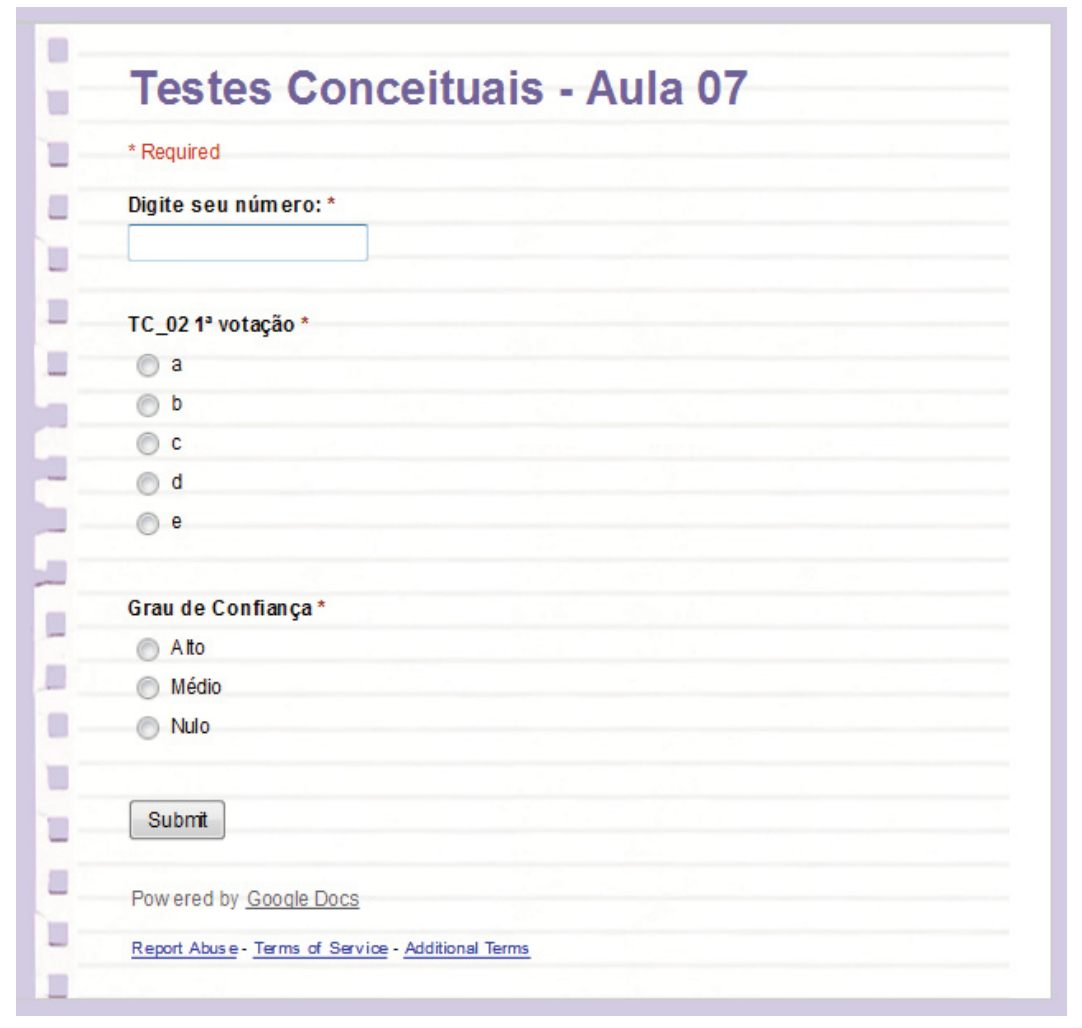

Fig. 2 - Formulário criado através do aplicativo Google Forms para as votações dos Testes Conceituais.

A escola em que o estudo foi desenvolvido já possuía os notebooks, um por estudante, pois, em 2010, foi uma das trezentas escolas selecionadas para participar do projeto-piloto do governo federal. Diversos projetos são desenvolvidos com o uso dos UCAs no colégio; contudo, os alunos do terceiro ano, por estarem no final do Ensino Médio, não participavam de nenhum projeto. A despeito do pouco contato com os computadores, os alunos da turma em que o estudo foi desenvolvido apresentavam certa habilidade em seu manuseio.

Ao longo da implementação do método, alguns obstáculos foram surgindo. Um deles foi a aversão dos estudantes em relação aos UCAs. Muitos alunos não simpatizavam com o uso dos notebooks em sala de aula, opinião manifestada espontaneamente já no primeiro encontro, em que foi mencionado que eles seriam 
utilizados para o desenvolvimento da nova metodologia de ensino. Os alunos, em geral, mostraram-se pessimistas em relação à funcionalidade, pois, para muitos, o notebook era muito lento e nunca funcionava direito. Cientes dessa aversão, aplicamos um questionário (Apêndice B) para coletar a opinião dos alunos em relação aos UCAs antes da implementação do método em si e logo após o último encontro. Os resultados encontrados serão discutidos na próxima seção.

Apesar de que alguns estudantes mantiveram suas críticas às características técnicas dos UCAs, sob a perspectiva do pesquisador e do professor, foi possível usá-los como sistema de votação para o IpC. Contudo, para isso, foi necessário muito trabalho antes de cada encontro. Foi indispensável checar cada computador para averiguar possíveis problemas com o sistema operacional, carregar totalmente as baterias dos trinta e quatro notebooks, levá-los até a sala de aula e distribuí-los de acordo com o espelho de classe sob as mesas dos alunos, além de criar os formulários no Google Forms para as votações.

Como forma de motivar os estudantes que participaram do estudo, os Testes Conceituais selecionados foram, em sua grande maioria, questões de vestibulares de instituições federais e particulares. Os alunos aprovaram o uso de questões de vestibulares como Testes Conceituais, sendo que muitos se mostravam extremamente entusiasmados quando acertavam tais questões. Atribuímos tal animação ao fato de que os mesmos prestariam vestibular ao final do ano e, ao acertarem, ganhavam confiança para realizar as provas futuras (vestibular).

Em média, três Testes Conceituais eram respondidos por encontro. Em todos os encontros, pelo menos um Teste Conceitual teve frequência de acerto entre $35 \%$ e $70 \%$, e houve a discussão entre os colegas, como propõe o método. $\mathrm{Na}$ sequência, os estudantes, individualmente, votaram novamente. A convergência das respostas nessa segunda votação para a alternativa correta é alvo de análise na próxima seção.

Apesar das resistências iniciais frente ao uso dos UCAs, os alunos se mostraram amplamente receptivos ao método. As discussões ocorreram de maneira harmoniosa e eles se mostraram motivados ao tentar convencerem os colegas que sua resposta estava correta.

A dinâmica proporcionada pelo IpC modificou a postura dos estudantes em sala de aula, principalmente nas aulas de sexta-feira à tarde, quando se observava que os mesmos se mostravam mais dispostos e concentrados, em comparação com as aulas expositivas dos dois meses que antecederam o uso do método. Ao responderem os Testes Conceituais, claramente notava-se certa obstinação em acertar. Em alguns encontros, ao final das votações, quando a frequência das respostas era divulgada e o resultado era positivo, os alunos se aplaudiam. 
Ao final do último encontro, com o intuito de obter mais informações sobre a opinião dos alunos, foi-lhes solicitado que respondessem ao questionário sobre os UCAs, que já haviam respondido antes da aplicação do IpC, acrescido de itens correspondentes à experiência com o método $\mathrm{IpC}$ e foi realizada uma entrevista semiestruturada com dez alunos. Tendo em vista que a pesquisa foi realizada no final do segundo semestre letivo, tivemos pouco tempo para entrevistar todos os alunos participantes da pesquisa; desse modo, selecionamos apenas dez, segundo os seguintes critérios: foram selecionados os oito alunos que obtiveram melhor desempenho em um teste conceitual ${ }^{8}$ realizado após o uso do $\mathrm{IpC}$ e os dois alunos que reclamavam com elevada frequência dos computadores utilizados.

Os dois instrumentos de medida (roteiro da entrevista semiestruturada e questionário) constam no Apêndice $\mathrm{B}$ e as informações obtidas com eles, bem como os demais resultados, são apresentados na próxima seção.

\section{Análise dos resultados obtidos}

A partir dos dados coletados em nossas observações de campo, com o questionário e as entrevistas (Apêndice B) e com os Testes Conceituais (Apêndice A), definimos quatro eixos de análise, a saber: atitude dos alunos em relação ao método IpC; atitude dos alunos em relação aos UCAs antes e depois de tê-los usado com o IpC; viabilidade do uso dos UCAs como sistema de votação do método $\mathrm{IpC}$; e a convergência das respostas para a alternativa correta na segunda votação, comparando-se com o que é apontado na literatura.

\section{V.1 Atitude dos alunos em relação ao método IpC}

Algumas afirmativas do questionário visavam investigar a atitude dos alunos em relação ao método IpC. Uma delas pretendia aferir a empatia dos alunos com aulas expositivas tradicionais. Essa afirmativa foi respondida antes e após a utilização do IPC. ${ }^{9}$

\footnotetext{
${ }^{8}$ A análise do teste conceitual aplicado aos estudantes após o IpC será feita na segunda etapa do projeto.

${ }^{9}$ As tabelas que contêm as perguntas que foram respondidas antes e após o uso do IPC apresentam número inferior ao total de alunos, pois utilizamos como dados apenas as respostas dos alunos que responderam aos dois questionários. As questões relacionadas especificadamente ao IpC apresentam trinta e três respondentes, visto que no dia tivemos ausência de um estudante.
} 
Cerca de $60 \%$ dos alunos responderam, na primeira aplicação do questionário, que "concordam" ou "concordam fortemente" que aprendem mais com aulas ditas tradicionais. Possivelmente essa marcante preferência por aulas tradicionais se deva à pouca vivência dos alunos com metodologias de ensino diferenciadas, visto que, após a implementação do IpC na sequência didática proposta, apenas $24 \%$ dos alunos "concordaram", ou "concordaram fortemente" com essa afirmativa. Além disso, houve um crescimento de $12 \%$ para $28 \%$ dos alunos que discordam da afirmativa de que aprendem mais com as aulas expositivas tradicionais. $\mathrm{Na}$ Tabela 1, também se pode obervar os percentuais em cada uma das demais alternativas.

Tabela 1 - Frequência de respostas dos alunos à seguinte afirmativa do questionário: Aprendo mais com aulas tradicionais (com uso de quadro negro e giz), antes e depois da implementação do IpC.

\begin{tabular}{|l|c|c|c|c|}
\hline \multirow{2}{*}{ Opinião } & \multicolumn{2}{c|}{ Antes } & \multicolumn{2}{c|}{ Depois } \\
\cline { 2 - 5 } & $\mathbf{N}^{\mathbf{0}}$ de respondentes & $\%$ & $\mathbf{N}^{\mathbf{0}}$ de respondentes & $\%$ \\
\hline $\begin{array}{l}\text { Concordo fortemen- } \\
\text { te }\end{array}$ & $\mathbf{6}$ & 24 & $\mathbf{2}$ & 8 \\
\hline Concordo & $\mathbf{9}$ & 36 & $\mathbf{4}$ & 16 \\
\hline Indiferente & $\mathbf{7}$ & 28 & $\mathbf{1 2}$ & 48 \\
\hline Discordo & $\mathbf{3}$ & 12 & $\mathbf{7}$ & 28 \\
\hline Discordo fortemente & $\mathbf{0}$ & 0 & $\mathbf{0}$ & 0 \\
\hline Total & $\mathbf{2 5}$ & 100 & $\mathbf{2 5}$ & 100 \\
\hline
\end{tabular}

Em específico, sobre o IpC, havia uma afirmativa em que os alunos manifestavam a sua opinião sobre a metodologia, sendo possível optar por alternativas que iam desde "muito boa" até "muito ruim". Pode-se observar, na Tabela 2, que aproximadamente $97 \%$ dos estudantes optaram pela opção "muito boa" ou "boa". Apenas 3\% dos respondentes consideraram "regular" e nenhum considerou "ruim" ou "muito ruim". 
Tabela 2 - Frequência de respostas dos alunos à seguinte afirmativa referente à avaliação do IpC: Dê sua avaliação sobre a metodologia utilizada nas últimas semanas.

\begin{tabular}{|l|c|c|}
\hline \multicolumn{1}{|c|}{ Opinião } & $\mathbf{N}^{\mathbf{0}}$ de respondentes & $\mathbf{\%}$ \\
\hline Muito ruim & $\mathbf{0}$ & 0 \\
\hline Ruim & $\mathbf{0}$ & 0 \\
\hline Regular & $\mathbf{1}$ & 3 \\
\hline Boa & $\mathbf{1 1}$ & 33 \\
\hline Muito boa & $\mathbf{2 1}$ & 64 \\
\hline Total & $\mathbf{3 3}$ & 100 \\
\hline
\end{tabular}

Alguns comentários na entrevista ratificaram as boas avaliações em relação ao método IpC:

Foi uma experiência diferente, a gente nunca teve uma aula assim. É um método novo, mas eu gostei. É evidente que "tu vai" aprender com ele, o professor explica e logo depois tem exercícios, como se fosse uma fixação, e, depois, com a discussão com os colegas, ajuda a fixar mais. (Aluno 33)

Eu achei muito bom o método, mas eu só achei ruim que ele foi usado no final do ano. Se tivéssemos usado desde o início do ano, com certeza os alunos teriam aprendido melhor. (Aluno 3)

O Aluno que optou pela opção "regular" na afirmativa 9 comentou, na entrevista:

\footnotetext{
Achei legal as questões apresentadas em aula, eu só acho que a gente tinha que ter interpretado mais em sala de aula, "tipo" conta [realização de exercícios numéricos] mesmo, não só a teoria. (Aluno 6)
}

$\mathrm{Na}$ sequência, os alunos responderam três questões dissertativas, as quais solicitavam, respectivamente, que destacassem os aspectos positivos da metodologia, os aspectos negativos e o que poderia ser feito para melhorar as aulas com o $\mathrm{IpC}$.

Quanto aos aspectos positivos da metodologia, a discussão entre os colegas foi o comentário mais presente. O linguajar mais simples do colega no momento da explicação, a tentativa de convencer o colega e a possibilidade de receber 
diferentes explicações sobre um mesmo tópico do conteúdo estiveram presentes em alguns comentários, como pode ser visto em suas palavras:

A discussão entre os alunos rende uma maneira de explicação diferente da habitual, pois os colegas entre si interagem de forma diferente do que a que o professor fala no quadro. Ajuda também os alunos a se concentrarem, pois os mesmos devem responder um questionário após a explicação. (Aluno 21)

Outro aluno afirmou ainda que:

Percebo que o Peer Instruction funcionou como deveria ter funcionado. Pôde promover a explicação de diversas dúvidas de um jeito mais simples, já que ouvíamos as respostas vindas de nossos colegas, pessoas que estamos mais acostumados a conversar e estabelecemos certo tipo de linguagem. (Aluno 25)

Além disso, os estudantes destacaram que o IpC possibilitou um aprendizado mais dinâmico, em que era possível pôr à prova seus conhecimentos logo em seguida da explicação do professor. Segundo um aluno, o aspecto positivo do IpC é:

Que TODOS conseguem aprender de uma forma nivelada e não apenas os alunos mais inteligentes. (Aluno 2)

Ainda na mesma linha, outras respostas foram:

Achei muito útil o método para exercitar o conteúdo e discutir com colegas a respeito da matéria, afinal, enquanto tentamos convencer os outros de que nossa ideia é a certa, acabamos, muitas vezes, percebendo nossos próprios erros e reforçando quando estamos corretos. (Aluno 9)

Através dela é possível reforçar conhecimentos, explicando-os aos colegas, e é possivel ouvir diversos tipos de explicações. (Aluno 15)

Alguns alunos destacaram que as aulas tornaram-se menos cansativas. As exposições ao longo da sequência didática não duraram mais do que trinta minutos, diferentemente das aulas expositivas anteriores ao método, que costumavam durar dois períodos de quarenta e cinco minutos cada. De acordo com os comentários dos alunos, as aulas expositivas anteriores faziam com que os estudantes perdessem o foco rapidamente e, por consequência, acabavam não aprendendo todo $o$ 
conteúdo. O IpC favoreceu os estudantes a manterem o foco e a atenção durante as explicações. Um dos comentários que evidencia tal opinião é reproduzido a seguir:

Eu achei mil vezes melhor que as aulas convencionais, que muitas vezes se tornam cansativas e desinteressantes. Quando o professor fica muito tempo explicando a matéria, muita gente acaba dispersando e indo pro mundo da lua e, além disso, é difícil de assimilar toda a matéria quando só ouvimos por dois períodos. (Aluno 30)

Além desse depoimento, destacamos outro que foi retirado das entrevistas:

Antes as aulas eram muito longas e, para explicar um ponto da matéria, a gente levava uma aula inteira. Com o método, as aulas ficaram mais dinâmicas. (Aluno 17)

Outro aspecto encontrado nos comentários dos alunos foi o desempenho no vestibular. Os Testes Conceituais selecionados para a sequência didática eram provenientes de vestibulares de instituições públicas e particulares. Um dos respondentes afirmou que:

Partindo do princípio de que estudamos para passar no vestibular, o fato de as aulas serem voltadas para questões deste facilita e aumenta fortemente nossas chances de passar no mesmo. (Aluno 22)

Outro aluno destacou que:

Achei que deu para compreender melhor as questões de vestibulares e analisar de outra forma essas mesmas questões. (Aluno 3)

Quanto aos aspectos negativos da metodologia, os estudantes destacaram as seguintes características: competitividade entre os colegas, falta de comprometimento de alguns estudantes durante as discussões e no início das aulas, a distração com o acesso a outros sites (redes sociais) e a falta de tempo para resolver os problemas do livro-texto. Um aluno afirmou que:

O que atrapalhou as aulas foi o fato de que as aulas demoravam muito pra começar e, de certa forma, perdíamos tempo com assuntos que não tinham nada a ver com o assunto de aula (Facebook, Twitter, etc.). (Aluno 12)

Durante a inserção do $\mathrm{IpC}$, a dispersão dos alunos com páginas na internet que não faziam parte do trabalho proposto foi algo presente. Alguns alunos mantiveram abertas, em segundo plano, suas páginas de redes sociais. Tivemos alguns 
problemas isolados com tal atitude, porém, nada que comprometesse seriamente o andamento da aula. Quando notávamos que o aluno estava muito disperso, pedíamos que fechasse momentaneamente o UCA e voltasse sua atenção para a aula.

Quanto a possíveis melhorias no método IpC em sala de aula, aproximadamente $47 \%$ dos estudantes afirmaram que, se outro sistema de votação fosse implementado, as aulas se tornariam mais produtivas e menos dispersas. Parte dos estudantes afirmou que seria bom bloquear o acesso às redes sociais para evitar dispersões, e parte afirmou que o UCA, apesar de ter funcionado corretamente, poderia ser mais veloz. Além disso, alguns alunos comentaram que faltou tempo para resolver os problemas do livro, bem como que poderíamos ter feito mais Testes Conceituais ao longo das aulas.

Tanto em relação aos aspectos negativos, quanto às sugestões de melhoria no método, a grande maioria dos comentários diz respeito à própria atuação dos alunos durante a aula. Ou seja, eles mesmos reconhecem que o tempo de aula poderia ser mais bem aproveitado.

O IpC proporcionou aos estudantes uma nova maneira de aprender os conteúdos de Física. As aulas tornaram-se mais dinâmicas e os alunos tornaram-se mais participativos. O entusiasmo foi marcante ao longo da inserção do método, principalmente em relação ao desempenho nos Testes Conceituais.

A discussão entre os colegas, ponto fundamental do método, proporcionou uma mudança na postura crítica dos estudantes. A argumentação crítica foi amplamente estimulada quando os mesmos apresentavam seus pontos de vista sobre um mesmo conceito presente nos Testes Conceituais. Incentivar uma postura crítica dos estudantes, através de discussões, vai ao encontro de uma das orientações do $\mathrm{PCN}+{ }^{10}$, qual seja:

Para desenvolver competências que requerem o sentido crítico, será necessário privilegiar espaços de discussão, tanto na escola como na sala de aula (BRASIL, 2002, p. 61).

A partir dos resultados aqui apresentados, bem como através da experiência vivenciada ao longo da sequência didática e das entrevistas, concluímos que, em geral, os alunos aprovaram a metodologia empregada.

\footnotetext{
${ }^{10}$ Documento que contém orientações complementares aos Parâmetros Curriculares Nacionais - PCN (BRASIL, 1999).
} 


\section{V.2 Atitude dos alunos em relação aos UCAs}

A fim de avaliar a atitude dos alunos em relação aos UCAs, foram feitas seis questões do tipo de escala de cinco níveis no questionário sobre esses equipamentos, apresentado no Apêndice B. A primeira delas focava-se na sua utilidade. Antes da metodologia IpC ser utilizada, apenas 36\% dos alunos concordavam que o UCA possuía alguma utilidade em sala de aula; após o IpC ser implementado, $68 \%$ dos alunos passaram a ter essa opinião. Além disso, teve-se uma redução no número de alunos que se mostraram indiferentes (de $36 \%$ para $8 \%$ ) ou discordantes (de $28 \%$ para $24 \%$ ).

Essa mudança de opinião também pode ser vista nas palavras dos próprios alunos:

O UCA é bom em alguns casos ou aulas, no caso do experimento de Física deu certo, até porque os professores conseguiram manter a ordem e não deixaram o uso do UCA atrapalhar a aula, até porque a aula era mais prática, então todos colaboraram e participaram. (Aluno 21)

A manifestação de outro aluno nesse mesmo sentido é apresentada a seguir:

O UCA nos ajudou bastante nas aulas de física, proporcionando-nos uma compreensão melhor da matéria. Isso devido ao modo em que ele foi utilizado, porém de outra maneira, como para fazer pesquisa, por exemplo, não é muito produtivo. (Aluno 8)

Também foram encontrados, nos comentários procedentes das entrevistas, indícios dessa mudança. Um dos respondentes afirmou que:

Antes eu achava que o UCA era um empecilho, agora eu acho que pode ser muito bem usado. (Aluno 17)

Em relação à motivação proporcionada pelo uso do UCA em sala de aula, antes do $\mathrm{IpC}, 68 \%$ dos alunos responderam que discordavam ou discordavam fortemente da afirmativa: "O uso do UCA, em sala de aula, me motiva a aprender". Muitos comentários ilustram essa opinião, principalmente em relação a problemas técnicos. Um dos mais marcantes é:

Para implantar fixamente o UCA no(s) colégio(s) é preciso melhorar muito mais seu funcionamento, para atrair mais os alunos a quererem usar como forma de estudo, e não apenas para "matação" de aula. (Aluno 11) 
No mesmo sentido, o aluno 5 afirmou:

Não gosto do UCA devido à baixa capacidade de processamento que possui, e ao seu tamanho, que é muito pequeno. (Aluno 5)

Após o IpC ser implementado, os alunos mostraram-se um pouco mais motivados. Cerca de $32 \%$ dos alunos "concordam" ou "concordam fortemente" que o UCA os motivou a aprender. A mesma percentagem é encontrada para os alunos que "discordam" ou "discordam fortemente" da afirmativa. Na Tabela 3, vê-se o percentual em cada uma dessas alternativas. Apesar de ter sido verificada uma redução do número de alunos que se sentiam desmotivados quanto ao uso do UCA em sala de aula, o percentual de alunos satisfeitos com o UCA fica bem aquém do desejável, provavelmente em decorrência dos alunos, ao responderem o questionário, não associarem a pergunta exclusivamente ao uso feito na disciplina de Física, ou seja, ao uso do UCA como sistema de votação para o IpC.

Os alunos não mudaram de opinião em relação à afirmativa que os UCAs, de certa forma, são uma distração em sala de aula (veja Tabela 4), conforme mostra a distribuição de respostas do questionário antes e depois do IpC. Tal concepção deve-se principalmente ao fato do livre acesso às redes sociais e a outros sites. Ao longo das aulas, tivemos algumas ocorrências de alunos acessando tais páginas. Uma medida possível de ser adotada é o bloqueio a tais sites.

Tabela 3 - Frequência de respostas dos alunos à afirmativa: o uso do UCA, em sala de aula, me motiva a aprender, antes e depois da aplicação do IpC.

\begin{tabular}{|l|c|c|c|c|}
\hline \multirow{2}{*}{\multicolumn{1}{c}{ Opinião }} & \multicolumn{2}{c|}{ Antes } & \multicolumn{2}{c|}{ Depois } \\
\cline { 2 - 5 } & $\mathbf{N}^{\mathbf{0}}$ de respondentes & $\%$ & $\mathbf{N}^{\mathbf{0}}$ de respondentes & $\%$ \\
\hline Discordo fortemente & $\mathbf{4}$ & 16 & $\mathbf{4}$ & 16 \\
\hline Discordo & $\mathbf{1 3}$ & 52 & $\mathbf{4}$ & 16 \\
\hline Indiferente & $\mathbf{4}$ & 16 & $\mathbf{9}$ & 36 \\
\hline Concordo & $\mathbf{4}$ & 16 & $\mathbf{7}$ & 28 \\
\hline Concordo fortemente & $\mathbf{0}$ & 0 & $\mathbf{1}$ & 4 \\
\hline Total & $\mathbf{2 5}$ & 100 & $\mathbf{2 5}$ & 100 \\
\hline
\end{tabular}


Tabela 4 - Frequência de respostas dos alunos à afirmativa: Os UCAs são uma distração em sala de aula, antes e depois da implementação do IpC.

\begin{tabular}{|l|c|c|c|c|}
\hline \multirow{2}{*}{\multicolumn{1}{c|}{ Opinião }} & \multicolumn{2}{c|}{ Antes } & \multicolumn{2}{c|}{ Depois } \\
\cline { 2 - 5 } & $\mathbf{N}^{\mathbf{0}}$ de respondentes & $\%$ & $\mathbf{N}^{\mathbf{0}}$ de respondentes & $\%$ \\
\hline Concordo fortemente & $\mathbf{1 0}$ & 40 & $\mathbf{6}$ & 24 \\
\hline Concordo & $\mathbf{1 0}$ & 40 & $\mathbf{1 2}$ & 48 \\
\hline Indiferente & $\mathbf{2}$ & 8 & $\mathbf{5}$ & 20 \\
\hline Discordo & $\mathbf{2}$ & 8 & $\mathbf{2}$ & 8 \\
\hline Discordo fortemente & $\mathbf{1}$ & 4 & $\mathbf{0}$ & 0 \\
\hline Total & $\mathbf{2 5}$ & 100 & $\mathbf{2 5}$ & 100 \\
\hline
\end{tabular}

Seguem alguns comentários de respondentes a esse respeito:

Acho que o UCA precisa de várias melhorias, pois ele distrai muito o aluno, principalmente para as redes sociais. (Aluno 3)

O UCA pode ser muito importante, mas, às vezes, ele é uma distração, por isso ele deve ser usado apenas para pesquisar e fazer as atividades sem ser liberado por toda a aula, e sim em parte dela. (Aluno 1)

Quanto à facilidade de manusear o UCA, de maneira geral, os alunos mudaram a intensidade de suas concordâncias ou discordâncias, mas em percentagens gerais não houve mudança. Somando as opções concordo e concordo fortemente, o percentual é o mesmo (68\%), no pré e pós-questionário, conforme a Tabela 5. Tal resultado está atribuído ao fato de que os estudantes tiveram uma interação com o computador pontual, ou seja, utilizaram apenas para votar nos Testes Conceituais. Não exploramos, no estudo realizado, outras ferramentas oferecidas por tal equipamento. Dessa forma, não houve mudanças quanto ao aspecto manuseio do computador.

Apenas um dos alunos mencionou que:

$$
\begin{aligned}
& \text { Após o uso mais regular dos UCAs em sala de aula, manuseá-lo tornou-se } \\
& \text { mais fácil. (Aluno 9) }
\end{aligned}
$$

$\mathrm{Na}$ aplicação final do questionário, 36\% dos alunos responderam que sentem facilidade em aprender o conteúdo quando utilizam o UCA, contrastado com o resultado de $52 \%$ na aplicação final do questionário (ver Tabela 6). Os alunos que 
apresentam uma posição contrária ao UCA mantiveram suas opiniões. Indicadores dessa postura contrária ao uso do UCA em sala de aula já foram aqui apresentados. Os respondentes que discordaram, ou discordaram fortemente, são os mesmos que se apresentaram adversos ao seu uso em outras afirmativas.

Tabela 5 - Frequência de respostas dos alunos à afirmativa: Tenho facilidade em manusear o UCA, antes e depois da implementação do IpC.

\begin{tabular}{|l|c|c|c|c|}
\hline \multirow{2}{*}{\multicolumn{1}{c|}{ Opinião }} & \multicolumn{2}{|c|}{ Antes } & \multicolumn{2}{c|}{ Depois } \\
\cline { 2 - 5 } & $\begin{array}{c}\mathbf{N}^{\mathbf{0}} \text { de respon- } \\
\text { dentes }\end{array}$ & $\%$ & $\begin{array}{c}\mathbf{N}^{\mathbf{0}} \text { de respon- } \\
\text { dentes }\end{array}$ & $\%$ \\
\hline Discordo fortemente & $\mathbf{0}$ & 0 & $\mathbf{2}$ & 8 \\
\hline Discordo & $\mathbf{5}$ & 20 & $\mathbf{3}$ & 12 \\
\hline Indiferente & $\mathbf{3}$ & 12 & $\mathbf{3}$ & 12 \\
\hline Concordo & $\mathbf{5}$ & 20 & $\mathbf{1 4}$ & 56 \\
\hline Concordo fortemente & $\mathbf{1 2}$ & 48 & $\mathbf{3}$ & 12 \\
\hline Total & $\mathbf{2 5}$ & 100 & $\mathbf{2 5}$ & 100 \\
\hline
\end{tabular}

Em relação a recomendar que os UCAs sejam utilizados com outros alunos (Tabela 7) houve, principalmente, indiferença. Indícios desse comportamento encontram-se nos comentários sobre as configurações técnicas dos UCAs. Outra possibilidade é que os estudantes, no questionário aplicado ao final, não tenham associado recomendar o uso do UCA em conjunto com o IpC.

Tabela 6 - Frequência de respostas dos alunos à afirmativa: Sinto facilidade em aprender o conteúdo quando utilizo o UCA, antes de depois da implementação do $\mathrm{IpC}$.

\begin{tabular}{|c|c|c|c|c|}
\hline \multirow[b]{2}{*}{ Opinião } & \multicolumn{2}{|l|}{ Antes } & \multicolumn{2}{|l|}{ Depois } \\
\hline & $\mathrm{N}^{\circ}$ de respondentes & $\%$ & $\mathbf{N}^{0}$ de respondentes & $\%$ \\
\hline Discordo fortemente & 2 & 8 & 1 & 4 \\
\hline Discordo & 4 & 16 & 5 & 20 \\
\hline Indiferente & 10 & 40 & 6 & 24 \\
\hline Concordo & 9 & 36 & 12 & 48 \\
\hline Concordo fortemente & $\mathbf{0}$ & 0 & 1 & 4 \\
\hline Total & 25 & 100 & 25 & 100 \\
\hline
\end{tabular}

Cad. Bras. Ens. Fís., v. 29, n. Especial 1: p. 491-524, set. 2012. 
Com grande frequência, os alunos responderam que parte de sua desmotivação em relação ao uso da ferramenta é causada por problemas técnicos, falta de capacidade de processamento, tela pequena, etc. Alguns comentários dos alunos apresentam tais opiniões:

A principal deficiência do UCA está em sua capacidade, tanto da velocidade de processamento quanto a da conexão. Uma forma de ter um maior aproveitamento do projeto é melhorar a capacidade do UCA. (Aluno 15)

O único problema do UCA é que o sistema ainda é primitivo, demorado, fazendo com que os alunos fiquem irritados com a demora. (Aluno 25)

O manuseio do UCA é bem complicado, principalmente quando vamos digitar algo. (Aluno 3)

O UCA deveria ser mais rápido, com o intuito de agilizar as tarefas desenvolvidas em sala de aula. (Aluno 22)

Apesar disso, o uso do UCA por meio do IpC mostrou aos alunos que existem maneiras de utilizar a ferramenta que não exigem muito tecnicamente, resultando em uma mudança de opinião quanto à utilidade dos UCAs e quanto à motivação dos alunos para usá-los.

Tabela 7 - Frequência de respostas dos alunos à afirmativa: Recomendo que os outros alunos usem o UCA, antes e depois da implementação do IpC. 7 do questionário.

\begin{tabular}{|c|c|c|c|c|}
\hline \multirow{2}{*}{ Opinião } & \multicolumn{2}{|l|}{ Antes } & \multicolumn{2}{|l|}{ Depois } \\
\hline & $\mathbf{N}^{0}$ de respondentes & $\%$ & $\mathrm{~N}^{0}$ de respondentes & $\%$ \\
\hline Discordo fortemente & 3 & 12 & 2 & 8 \\
\hline Discordo & 7 & 28 & 3 & 12 \\
\hline Indiferente & 7 & 28 & 13 & 52 \\
\hline Concordo & 6 & 24 & 7 & 28 \\
\hline Concordo fortemente & 2 & 8 & $\mathbf{0}$ & 0 \\
\hline Total & 25 & 100 & 25 & 100 \\
\hline
\end{tabular}




\section{V.3 Viabilidade do uso do UCA como sistema de votação do método IpC}

Para conhecer a opinião dos alunos sobre o uso dos UCAs como sistema de votação do método IpC, uma das afirmativas do questionário era: "O UCA funcionou muito bem como sistema de votação para o IpC", frente à qual os alunos deveriam se posicionar em uma escala de concordância com cinco níveis (escala Likert). Dos trinta e três respondentes (um estudante não estava presente no dia em que o questionário foi aplicado), dezesseis optaram pela alternativa concordo fortemente, doze pela alternativa concordo, apenas quatro dos respondentes discordaram e um se manifestou indiferente.

Os respondentes que discordaram são os mesmos que, ao longo do questionário, apresentaram uma posição enfaticamente contrária aos UCAs, mesmo após o IpC ser utilizado. Eles não simpatizavam com os UCAs devido às suas características técnicas inferiores aos dispositivos eletrônicos que esses alunos já utilizam há algum tempo em casa. Apesar da insatisfação de quatro alunos, a maior parte aprovou os UCAs como sistema de votação para o IpC, conforme pode ser visto, por exemplo, nesse comentário expresso no questionário:

Utilizar o UCA para a metodologia que estamos trabalhando em aula é útil, porém têm outros exercícios de outras matérias em que o UCA não facilita o aprendizado. (Aluno 29)

Outras manifestações semelhantes foram constadas nas entrevistas semiestruturadas:

O jeito que a gente usou é um jeito eficiente porque não precisa exigir muito do computador. Porque o computador não é "muito dos melhores". (Aluno 2)

O UCA em si é muito lento, mas "do jeito que ele foi bem empregado". (Aluno 17)

Apesar dos muitos comentários dos alunos em relação aos problemas técnicos do UCA, foi possível utilizá-los como sistema de votação, pois, para tanto, não é requerida capacidade maior do que a apresentada pelos mesmos, e não houve qualquer contratempo, porque, precavidamente, organizamos seu uso de modo que sempre estivessem com suas baterias carregadas. Além disso, o Google Forms constitui-se em um recurso muito útil para a coleta e rápida análise dos dados. 


\section{V.4 Convergência para a resposta correta}

Para investigarmos a convergência para a resposta correta dos testes propostos sobre conteúdos de Eletromagnetismo quando os alunos são postos a discutir entre eles, fizemos uma análise descritiva de todos os Testes Conceituais utilizados neste trabalho. No total, foram respondidos pelos alunos vinte e um Testes Conceituais. Destes, doze tiveram frequência de acertos entre $35 \%$ e $70 \%$ e, portanto, conforme o IpC propõe, os alunos discutiram entre si. Apenas um Teste Conceitual teve frequência de acerto inferior a $35 \%$ e o tópico foi retomado. No restante dos Testes Conceituais, o desempenho foi superior a $70 \%$.

A Fig. 3 sintetiza os resultados correspondentes às doze questões em que houve duas votações. Cada coluna é identificada pelo código $a_{n} \_q_{m}$, onde $n$ representa o número da aula $(1,2,3$, etc.) e $m$ representa o número da questão. Na construção desse gráfico, foi levada em conta a resposta de cada aluno na primeira e na segunda votação, e seu desempenho no Teste Conceitual foi classificado nas seguintes categorias:

- correto para incorreto, quando o aluno optou pela resposta correta e, depois da discussão entre os colegas, optou pela opção incorreta;

- correto duas vezes, quando o aluno optou pela resposta correta antes e após a discussão;

- incorreto duas vezes, quando o aluno optou pela resposta incorreta antes e após a discussão;

- incorreto para correto, quando o aluno optou pela resposta incorreta e, após a discussão, optou pela resposta correta.

Observa-se, na Fig. 3, que a discussão entre os colegas favoreceu a convergência para a resposta correta. Em algumas votações, tivemos alunos que mantiveram sua resposta incorreta; entretanto, o percentual foi baixo, comparativamente. Em três questões com discussão entre os colegas, tivemos 100\% de convergência para a resposta correta, ou seja, todos os estudantes que marcaram a resposta incorreta foram convencidos pelos colegas que optaram pela resposta correta.

Consideramos que os estudantes tiveram um desempenho expressivamente positivo ao longo das discussões. Em todos os Testes Conceituais que tiveram discussões, a convergência ocorreu apenas para a resposta correta, e não se verificou nenhum caso em que a convergência ocorreu para a resposta incorreta.

É possível observar que, no estudo realizado, encontramos de maneira significativa a convergência para a resposta correta, conforme aponta a literatura (MAZUR, 1997; CROUCH et al., 2007; CROUCH; MAZUR, 2001; BUTCHART et al., 2009). 


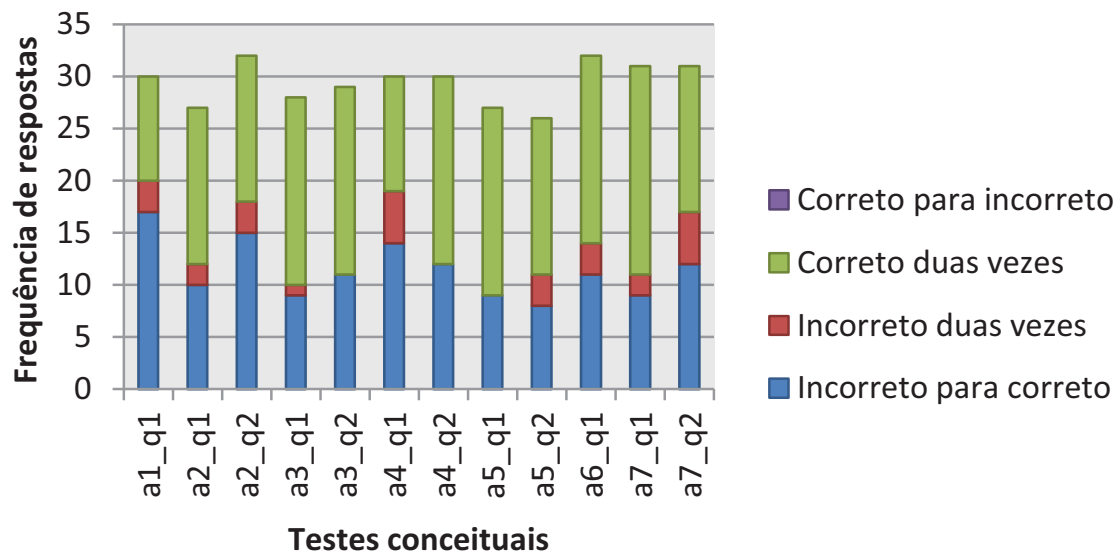

Fig. 3 - Distribuição de frequência de respostas para os 12 Testes Conceituais em que ocorreram discussões entre os colegas.

\section{Considerações finais}

Relatamos, neste trabalho, uma experiência relativamente bem sucedida em relação ao uso do método IpC, em uma turma de alunos do Ensino Médio. Através do estudo realizado, concluímos que é possível utilizar os notebooks do projeto UCA como sistema de votação, e também encontramos, de maneira satisfatória, a convergência para a resposta correta dos testes propostos de maneira semelhante à apontada na literatura.

Os alunos participantes do estudo mostraram-se motivados com a nova metodologia. A discussão entre os colegas, e o fato de as aulas terem se tornado menos cansativas para os alunos, foram comentários frequentes quando indagados sobre os aspectos positivos da metodologia. Além disso, a forma como o UCA foi utilizado ao longo do estudo favoreceu a mudança parcial de opinião dos estudantes a respeito dessa ferramenta. Alguns destacaram que o UCA, na experiência didática proposta na disciplina de Física, funcionou de maneira satisfatória.

Entretanto, para que o uso do UCA como sistema de votação para o IpC fosse apropriado, foi necessário tomar algumas medidas preventivas, as quais tornaram o trabalho do professor e do pesquisador bastante cansativo, principalmente no que se refere às condições técnicas. Foi imprescindível testar e carregar as baterias de todos os notebooks antes dos encontros, pois, em média, a autonomia dos UCAs utilizados estava em torno de duas horas. Além disso, foi necessário levá-los 
para a sala de aula, visto que eram armazenados em uma sala específica na escola, intensificando ainda mais o trabalho do pesquisador e do professor para organizar os episódios de ensino.

Dessa forma, ao analisarmos a viabilidade do uso dos UCAs, concluímos que, apesar de a ferramenta poder ser utilizada para implementar o método, de fato, em condições em que o professor não conta com suporte de um técnico para organização e tem várias turmas para atender, não é viável utilizá-la. Em outras palavras, um professor que atua sozinho em sala de aula teria seu trabalho significativamente aumentado ao utilizar os notebooks educacionais como ferramentas de votação para o IpC.

As ações tomadas, descritas anteriormente, foram necessárias para o bom andamento da aula. Contudo, outras medidas que não foram adotadas ao longo da pesquisa podem ser incluídas como, por exemplo, bloquear o acesso às redes sociais ou aos sites indesejados, evitando, assim, uma possível dispersão da atenção dos alunos.

Tendo em vista que boa parte dos comentários negativos dos estudantes são a respeito dos UCAs, e também que a maior dificuldade de implementação em sala de aula do IpC estava relacionada com as especificações técnicas dos notebooks utilizados, uma questão pertinente seria analisar as vantagens deles em relação aos clickers, por exemplo. Em linhas gerais, os clickers são dispositivos que possuem uma finalidade muito específica, qual seja, permitir votações eletrônicas. A convergência de funções encontradas em dispositivos com acesso à internet, tais como computadores pessoais e smartphones, simplesmente não é possível com os clickers. Assim, eles passariam a ser mais um aparelho que os alunos teriam que utilizar em salas de aula em que os UCAs estão disponíveis.

Acreditamos que a melhor estratégia seja, ainda, investir em apenas um equipamento que possa ser usado para diversos fins, mas com melhores especificações técnicas que os UCAs atuais. Um exemplo disso são os tablets, que, mesmo em versões mais econômicas, possuem, em média, um tempo maior de duração da carga da bateria (cerca de dez horas) e, devido ao seu peso e às suas dimensões, oferecem uma mobilidade superior aos notebooks.

Nesse contexto, pode então ser muito bem-vinda a notícia divulgada no portal do MEC ${ }^{11}$, onde é enunciado que o Governo Federal está tomando providências para a distribuição de tablets para professores e gestores de escolas públicas.

${ }^{11}$ Disponível em:

$<$ http://portal.mec.gov.br/index.php?option=com_content\&view=article \&id=17479:minister io-distribuira-tablets-a-professores-do-ensino-medio\&catid=215>. Acesso em: 02 fev. 2012. 
Isso leva a crer que, em breve, esse recurso também chegará às mãos dos alunos, facilitando a possibilidade de inserção do IpC em escolas de nível médio.

Todavia, reiteramos que são necessárias medidas políticas e pedagógicas que aproveitem ao máximo as potencialidades dessas ferramentas. Treinamento para os professores, bem como o acompanhamento dos projetos desenvolvidos nas escolas, são de extrema importância. Apenas a presença de notebooks, ou até mesmo dos tablets, em sala de aula, não promoverá o alcance dos resultados de aprendizagem pretendidos; é necessário que tais ferramentas sejam utilizadas por professores capacitados e cientes de suas potencialidades.

Com esse intuito, o presente trabalho relatou, em específico, uma possível utilidade dos UCAs: seu uso como sistema de votação eletrônica para a implementação do método IpC. No entanto, como salientamos antes, essa ferramenta apresenta diversas outras funcionalidades que podem e devem ser exploradas no ambiente escolar.

A participação ativa dos alunos em sala de aula, aliada aos comentários positivos em relação ao método, mostram que é possível, através do método IpC, modificar a dinâmica de sala de aula, aumentando significativamente a interação interpessoal e a motivação dos alunos. Ao inserir o método, existe a possibilidade de intercalar aulas utilizando o IpC com atividades de resolução de problemas, trabalho experimental e/ou simulação computacional, voltadas para o ensino.

Como perspectiva de continuação do trabalho, pretendemos avaliar o desempenho de estudantes com aulas utilizando o IpC e de estudantes com aulas do tipo expositiva. Dessa forma, planeja-se investigar mais profundamente as interações que se estabelecem entre os alunos e destes com o professor, bem como a contribuição do método para uma aprendizagem significativa dos conteúdos disciplinares por parte dos alunos.

\section{Referências}

BRASIL. PCN+ Ensino Médio: Orientações Educacionais Complementares aos Parâmetros Curriculares nacionais - Ciências da Natureza, Matemática e suas Tecnologias. Brasília: MEC; SEMTEC, 2002.

BRASIL. Parâmetros Curriculares Nacionais: Ensino Médio. Brasília: MEC; SEMT, 1999. 
BUTCHART, S; HANDFIELD, T; RESTALL, G. Using Peer Instruction to teach Philosophy, Logic and Critical Thinking. Teaching Philosophy. v. 32, n. 1, p. 140, 2009.

CROUCH, C. H.; MAZUR, E. Peer Instruction: Ten years of experience and results. American Journal of Physics, v. 69, n. 9, p. 970-977, 2001.

CROUCH, C. H.; WATKINS, J.; FAGEN, A. P.; MAZUR, E. Peer Instruction: Engaging Students One-on-One, All At Once. Research-Based Reform of University Physics. v. 1, p. 1-55, 2007.

GOWIN, D. B. Educating. Ithaca: NY, Cornell University Press, 1981. 210 p.

FAGEN, A. P. Peer Instruction: Results from a Range of Classrooms. The Physics Teacher. v. 40, n. 4, p. 206-209, 2002.

LASRY, N. Clickers or Flashcards: Is There Really a Difference? The Physics Teacher, v. 46, n. 4, p. 242-244, 2008.

MAZUR, E. Peer instruction: A user's manual. Upper Saddle River, N. J. Prentice Hall, 1997. 253 p.

MOREIRA, M. A. Metodologias de Pesquisa em Ensino. 1. ed. São Paulo: Livraria da Física, 2012.

NOVAK, G. M.; PATTERSON, E. T.; GAVRIN, A. D.; CHRISTIAN, W. JustIn-time teaching: blending active learning with web technology. Upper Saddle River, N. J. Prentice Hall, 1999. 188 p.

NOVAK, J. D. Uma Teoria de educação. São Paulo: Pioneira, 1981. 252 p.

VALENTE, J. A. Diferentes Usos do Computador na Educação. Em Aberto, Brasília, 12, n. 57, p. 3-16, jan./mar. 1993.

VYGOTSKY, L. S. A formação Social da Mente: o desenvolvimento dos processos psicológicos superiores. 4. ed. São Paulo: Martins Fontes, 1991.

YIN, R. K. Estudo de caso: planejamento e métodos. 3. ed. São Paulo: Bookmanm, 2005. 234 p. 


\section{Agradecimentos}

Agradecemos à Prof ${ }^{a}$. Neusa Teresinha Massoni e ao aluno do Programa de Pós-Graduação em Ensino de Física Alex Soares Vieira pelas críticas e sugestões ao presente trabalho.

\section{Apêndice A}

Neste apêndice, apresentamos alguns exemplos de testes conceituais propostos aos estudantes.

- Teste Conceitual - Aula 01

(UFRGS) Um fio retilíneo e muito longo, percorrido por uma corrente elétrica constante, é colocado perpendicularmente ao plano da página no ponto P. Se o campo magnético da Terra é desprezível em relação ao produzido por essa corrente, qual o número que indica corretamente o alinhamento da agulha magnética?
(a) 1
(b) 2
(c) 3
(d) 4
(e) 5

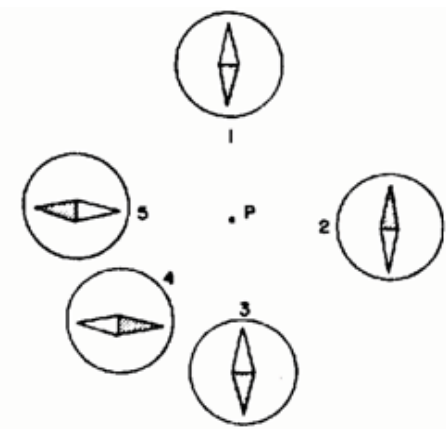

- Teste Conceitual - Aula 2

(PUC-RS) Uma espira circular é colocada sobre o mostrador de um relógio (antimagnético) com os centros coincidindo. $\mathrm{Na}$ espira há uma corrente elétrica que circula no sentido horário. Sobre o vetor campo magnético no centro do relógio pode-se afirmar que:

(a) É nulo.

(b) Tem sentido para dentro, segundo o eixo do relógio.

(c) É perpendicular ao eixo.

(d) Tem sentido para fora, segundo o eixo do relógio.

(e) É impossível determinar o sentido deste vetor campo magnético.

- Teste Conceitual - Aula 06

(UEL-PR, modificada) Uma espira circular está imersa em um campo magnético. O gráfico representa o fluxo magnético através da espira em função do tempo. 
O intervalo de tempo em que não aparece na espira uma corrente elétrica induzida é de:
(a) $1 \mathrm{~s}$ a $3 \mathrm{~s}$, somente
(b) $0 \mathrm{~s}$ a $1 \mathrm{~s}$, somente
(c) $0 \mathrm{~s}$ a $3 \mathrm{~s}$, somente
(d) $2 \mathrm{~s}$ a $3 \mathrm{~s}$, somente
(e) $1 \mathrm{~s}$ a $2 \mathrm{~s}$, somente

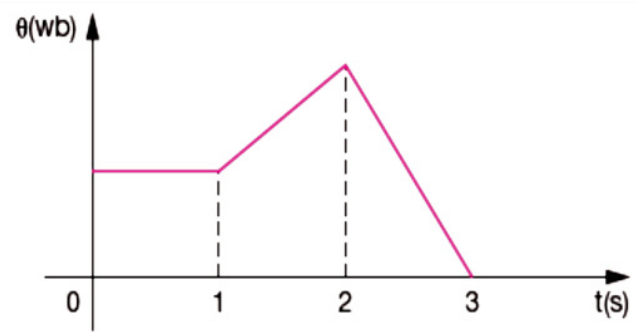

\section{Apêndice B}

Neste apêndice, apresentamos o questionário que os alunos responderam sobre o UCA e sobre o método IpC, assim como o roteiro da entrevista semiestruturada realizada.

\section{- Questionário sobre o uso do UCA e o método IpC}

Este questionário continha duas partes, uma relativa ao UCA (itens 1 a 8 ) e outra relativa ao método IpC (itens 9 a 14). Os itens 1 a 7 são afirmativas de múltipla escolha, sobre as quais o aluno deveria manifestar a sua opinião em uma escala de cinco níveis (Concordo Fortemente, Concordo, Indiferente, Discordo e Discordo Fortemente) e um item com resposta aberta do tipo dissertativa, com os seguintes enunciados.

01 - Acho útil utilizar o UCA em sala de aula.

02 - O uso do UCA, em sala de aula, me motiva a aprender.

03 - Os UCAs são uma distração em sala de aula.

04 - Tenho facilidade em manusear o UCA.

05 - Aprendo mais com aulas tradicionais (com o uso de quadro negro e giz).

06 - Sinto facilidade em aprender o conteúdo quando utilizo o UCA.

07 - Recomendo que outros alunos usem o UCA.

08 - Deixe comentários e sugestões sobre o uso do UCA. 


\section{- Itens relativos ao método IpC}

A afirmativa 9 é de múltipla escolha, com escala de cinco níveis, variável entre Muito boa a Muito ruim. As afirmativas 10 e 11 são de múltipla escolha, com escala de cinco níveis, variável de Concordo Fortemente a Discordo Fortemente. Os itens 12 a 14 são do tipo resposta aberta do tipo dissertativa.

09 - Dê sua avaliação sobre a metodologia utilizada nas últimas semanas.

10 - O UCA funcionou muito bem como sistema de votação para o Peer Instruction.

11 - O Peer Instruction irá melhorar meu desempenho no vestibular.

12 - Na sua opinião, quais os aspectos positivos da metodologia?

13 - Na sua opinião, quais os aspectos negativos da metodologia?

14 - Na sua opinião, o que poderia ser feito para melhorar?

\section{- Roteiro da entrevista semiestruturada}

1. Ao entrarmos no cap. 23, trabalhamos de um jeito diferente do que vínhamos fazendo. Poderias falar um pouco sobre a tua experiência, quer dizer, o que achaste dela, em geral?

2. Quanto ao uso do UCA, o que achaste da maneira como ele foi utilizado em sala de aula?

3. A tua opinião sobre o UCA mudou, comparando com a que tinhas antes de trabalhar com eles para votação das respostas?

4. Quanto à apresentação dos testes conceituais e às votações em sala de aula, o que achaste?

5. Qual a tua opinião sobre a discussão das respostas com os colegas? Achas que foi útil, que conseguiste aprender melhor com isso?

6. Consideras que tenhas aprendido os conteúdos de Física trabalhados?

7. Achas que a nova metodologia irá ajudar-te a ter um desempenho melhor no vestibular?

8. Quanto ao tempo para a votação e/ou discussão com os colegas em aula, achaste suficiente? 
9. Pensando que essa forma de ensinar poderá ser usada novamente com as novas turmas que chegam a essa disciplina no ano que vem, o que poderia ser feito para melhorar?

10. Há alguma outra coisa que não foi perguntada, mas que gostarias de mencionar em relação à tua experiência? 